LAPEÑA GALLEGO, Gloria (2016): "El lenguaje fotográfico de maquetas arquitectónicas como forma de expresión creativa". Ángulo Recto. Revista de estudios sobre la ciudad como espacio plural, vol. 8, núm. 1-2, pp. 113-126. ISSN: 1989-4015.

http://dx.doi.org/10.5209/rev_ANRE.2016.v8.n1.53351

\title{
EI lenguaje fotográfico de maquetas arquitectónicas como forma de expresión creativa ${ }^{1}$
}

\author{
Gloria LAPEÑA GALLEGO \\ Departamento de Bellas Artes \\ Universidad de Murcia \\ gloria.lapena@um.es
}

Recibido: 29/02/2016

Modificado: $15 / 06 / 2016$

Aceptado: 30/06/2016

\section{Resumen}

Mediante el presente estudio de investigación establecemos una conexión entre las maquetas que diseña el arquitecto como herramienta para proyectar la construcción de un edificio en el espacio urbano y las maquetas de escenarios elaboradas por el fotógrafo con fines artísticos. El objetivo principal es poner evidencia de qué manera las fotografías de maquetas descontextualizadas de su funcionalidad como proyectos de viviendas aíslan los edificios de su cotidianidad en el espacio público, conformando otros estratos de percepción del tiempo, el lugar y la memoria. Su finalidad, más allá de lo puramente arquitectónico, extravasa el nivel de la mimesis o de la duplicidad de la mirada, previa a la materialización de una construcción. Para alcanzar nuestro objetivo, analizamos la obra de cuatro artistas contemporáneos, cuya metodología se basa en el diseño y creación de maquetas arquitectónicas como paso previo a la captura de la fotografía.

Palabras clave: arte contemporáneo, fotografía, maqueta arquitectónica.

Title: The Photographic Language Models as an Architectural Creative Expression

\section{Abstract}

In this study we relate the architectural models designed by the architect as a tool to project the construction of a building in the urban space and the architectural scenarios created by the photographer for artistic purposes. The main aim is to know how the photographs of decontextualized scenarios isolate the buildings of their functionality in the public space, forming new perceptions of time, place and memory. Its purpose goes beyond the purely architectural, that is to say, it exceeds the level of mimesis or the duplicity of the gaze,

${ }^{1}$ Este trabajo de investigación forma parte de la Tesis Doctoral financiada con una ayuda predoctoral (19099/FPI/13) con cargo al Programa de Formación del Personal Investigador de la Fundación Séneca, Agencia de Ciencia y Tecnología de la Región de Murcia, en el marco del III PCTRM 2011-2014. 
LAPEÑA GALLEGO, Gloria (2016): "El lenguaje fotográfico de maquetas arquitectónicas como forma de expresión creativa". Ángulo Recto. Revista de estudios sobre la ciudad como espacio plural, vol. 8, núm. 1-2, pp. 113-126. ISSN: 1989-4015.

http://dx.doi.org/10.5209/rev_ANRE.2016.v8.n1.53351

previously to the materialization of any construction. To reach our aim, we analyze the work of four contemporary artists, whose methodology is based on the design and construction of architectural scenarios as a first step before capturing the photograph.

Keywords: contemporary art, photography, architecture model.

\section{Índice}

1. Introducción

2. Arquitectura: arte o técnica

3. El arquitecto y el artista: puntos de encuentro

4. El artista como constructor de maquetas

4.1. James Casebere

4.2. Thomas Demand

4.3. Ignacio Llamas

4.4. Gloria Lapeña

5. Conclusiones

\section{Introducción}

A lo largo de la Historia, la Arquitectura como área de las Bellas Artes se ha asociado con la proyección de edificios y monumentos para ser dedicados al culto 0 a la residencia de familias de cierto nivel económico, atendiendo al estilo y estética de la época. A principios del siglo XX, reconocidos arquitectos como Loos y Le Corbusier proyectan formas geométricas puras, con una estética acorde al desarrollo tecnológico. Las casas habitables pierden el carácter de exclusividad y de "pieza única", pasando a ser un objeto técnico, tendiendo a ajustar al máximo la economía de materiales y espacios, sin olvidar las condiciones legales. Sin embargo, no se renuncia al aspecto creativo, lo que propicia el reconocimiento de algunos arquitectos como verdaderos artistas. Tanto la arquitectura como la fotografía comparten fases previas a la obra final, y una de ellas son los escenarios-simulaciones, concretamente las maquetas.

La construcción de una maqueta en arquitectura está relacionada con la noción de la escala, herramienta que no siempre ha estado presente a lo largo de la Historia. Así, los griegos no consideran la ampliación o reducción de cualquier elemento arquitectónico, y trabajan siempre a escala 1:1. En Roma, la escala se introduce como un instrumento imprescindible para aumentar o disminuir, respetando las proporciones, el tamaño de la construcción, o para variar la combinación y número de elementos, pasando, por ejemplo, de una bóveda de veinte metros en el centro, a cuatro de cinco metros (Plá, Garnica y Esparza 2006). En la actualidad, a pesar de los medios digitales que ofrecen una 
LAPEÑA GALLEGO, Gloria (2016): "El lenguaje fotográfico de maquetas arquitectónicas como forma de expresión creativa". Ángulo Recto. Revista de estudios sobre la ciudad como espacio plural, vol. 8, núm. 1-2, pp. 113-126. ISSN: 1989-4015.

http://dx.doi.org/10.5209/rev_ANRE.2016.v8.n1.53351

perspectiva real del futuro edificio, la maqueta sigue utilizándose para proyectar, para mostrar y para experimentar.

En cuanto a la primera finalidad, algunos proyectos sometidos a concurso son difíciles de representar en un dibujo para convencer al jurado. Además, hay un problema de estereotomía que se resuelve con la maqueta. El arquitecto es consciente del poder explicativo de los bocetos escultóricos sobre las tergiversaciones a las que se someten los planos bidimensionales, especialmente si el proyecto es complejo (Úbeda Blanco 2002). Basta citar el proyecto de Arata Isozaki para el concurso del Guggenheim de Bilbao en 1991. Su representación lineal, muy sintética, no pudo compararse con el impacto visual y formal de las maquetas de Gehry (Falcón Meraz 2008).

Por otra parte, el arquitecto conoce el potencial expresivo de la maqueta sobre la representación lineal. Como señala Dondis (1980: 78), "la construcción de una maqueta es probablemente la única manera de mostrar a personas de poca sensibilidad para la visualización qué aspecto tendrá el objeto una vez terminado".

La finalidad de experimentar por medio de las maquetas arquitectónicas, y que tiene que ver con el arte, es el proceso creativo de ideación y representación de un proyecto arquitectónico. Una práctica en la arquitectura y en la escultura consiste en dibujar con los ojos cerrados y traducirlo a maqueta. "Cuanto más simultáneo sea el proceso de traducción del boceto a la maqueta, mayor será la disminución del efecto del boceto adquiriendo la maqueta una mayor importancia" (Werner apud Zugmann 2002: 35). La maqueta se emancipa como objeto, adquiere autonomía y deja de ser una misma realidad a dos escalas para mostrar el resultado del proyecto (Plá, Garnica y Esparza 2006).

Algunos fotógrafos han aprovechado esta cualidad de las maquetas y han construido sus propios ambientes para controlar y dirigir la mirada hacia aquello que captan intencionadamente con el objetivo de la cámara. Es este aspecto el que vamos a desarrollar en este estudio. Para ello, realizamos una búsqueda de obras de fotógrafos que construyen maquetas de edificios reales o imaginarios, y que posteriormente captan sus interiores con el fin de llevar al espectador a la reflexión sobre temas cotidianos, al mismo tiempo que producen una sensación de extrañeza y tensión. La obra resultante se aproxima más a la expresividad y al poder de la imagen, sin importar su posibilidad o imposibilidad de ser habitada físicamente, para alejarse de tecnicismos propios de una maqueta arquitectónica. Mostramos cuatro proyectos cuya intención es crear una narrativa en torno a arquitecturas descontextualizadas expuestas en la galería de arte, otorgándole un 
LAPEÑA GALLEGO, Gloria (2016): "El lenguaje fotográfico de maquetas arquitectónicas como forma de expresión creativa". Ángulo Recto. Revista de estudios sobre la ciudad como espacio plural, vol. 8, núm. 1-2, pp. 113-126. ISSN: 1989-4015.

http://dx.doi.org/10.5209/rev_ANRE.2016.v8.n1.53351

nuevo significado. El objetivo es la investigación de nuevos lenguajes fotográficos a través de espacios cotidianos, la casa como lugar que se habita, presentados distantes e inquietantes.

Con el fin de estructurar el artículo, comenzaremos por plantear la arquitectura como ciencia multidisciplinar, abarcando áreas que tienen que ver con la estética, otras con la funcionalidad, e incluso algunas como la Antropología, que intentan centrarse en la identidad social del grupo al que va a ser destinada. Este aspecto sitúa al arquitecto en campos pertenecientes a la técnica y al arte, en ocasiones difíciles de segregar. Por último, sometemos a análisis cuatro obras fotográficas que muestran maquetas arquitectónicas construidas por el artista con una finalidad estética.

\section{Arquitectura: arte o técnica}

La arquitectura, o el arte de proyectar y construir edificios, es una profesión universitaria cuya formación consiste en dotar al futuro arquitecto de las competencias necesarias con el fin de diseñar y crear espacios para el uso y comodidad de los seres humanos. Esta definición, que responde a la época actual, en la que los edificios se construyen buscando una funcionalidad, fue vislumbrada a principios del siglo XX. Loos, apelando a consideraciones morales y económicas, rompe con toda la narrativa ornamental de las casas vienesas a favor de una arquitectura más funcional (Hergueta Piorno 2012). El propio arquitecto, en su libro Escritos II, refiere del siguiente modo lo que debe ser una casa habitable:

La casa debe agradar a todos, a diferencia de la obra de arte, que no tiene por qué gustar a nadie. La obra de arte es un asunto privado del artista. La casa no lo es. La obra de arte se sitúa en el mundo sin que exista exigencia alguna que la obligue a nacer. La casa cubre una exigencia. [...] La obra de arte es revolucionaria, la casa es conservadora. [...] ¿no será que la casa no tiene nada que ver con el arte y que la arquitectura no debiera contarse entre las artes? Así es. Solo una parte, muy pequeña, de la arquitectura corresponde al dominio del arte: el monumento funerario y el conmemorativo. Todo lo demás, todo lo que tiene una finalidad hay que excluirlo del imperio del arte. (Loos 1993: 33)

Le Corbusier, por su parte, en su libro Hacia una arquitectura (1978), realiza una recopilación de artículos y escritos que aparecieron por primera vez en 1958 bajo el título La Collection de l'Esprit Nouveau. El arquitecto critica las fórmulas academicistas y dicta advertencias en cuanto a volumen, superficie y plan para ingenieros y arquitectos, con el 
fin de encontrar soluciones renovadoras para la casa. Su espíritu y su preocupación por el orden matemático quedan de manifiesto especialmente en el capítulo "Trazados reguladores", en el que mediante líneas sobre las fotografías de monumentos y casas realiza cálculos geométricos. Esta idea modular de repetición tiene también un reflejo en la eliminación de todo lo superfluo para conseguir una casa funcional a la altura de cualquier avance tecnológico, como una máquina de habitar. No obstante, para Le Corbusier, la arquitectura sigue conservando la categoría de Arte. Son famosas las fotografías del arquitecto junto a la maqueta de la Ville Savoy, construida en Poissy, París, en 1929 y expuestas en el MoMA en 1932 (figura 1). En su libro Vers une Architecture escribe:

La arquitectura está más allá de los hechos utilitarios. La arquitectura es un hecho plástico. [...] La arquitectura es el juego sabio, correcto, magnífico de los volúmenes bajo la luz. [...] Su significado y su tarea no es solo reflejar la construcción y absorber una función, si por función se entiende la de la utilidad pura y simple, la del confort y la elegancia práctica. La arquitectura es arte en su sentido más elevado, es orden matemático, es teoría pura, armonía completa gracias a la exacta proporción de todas las relaciones: ésta es la función de la arquitectura. (Le Corbusier 1978: 7)

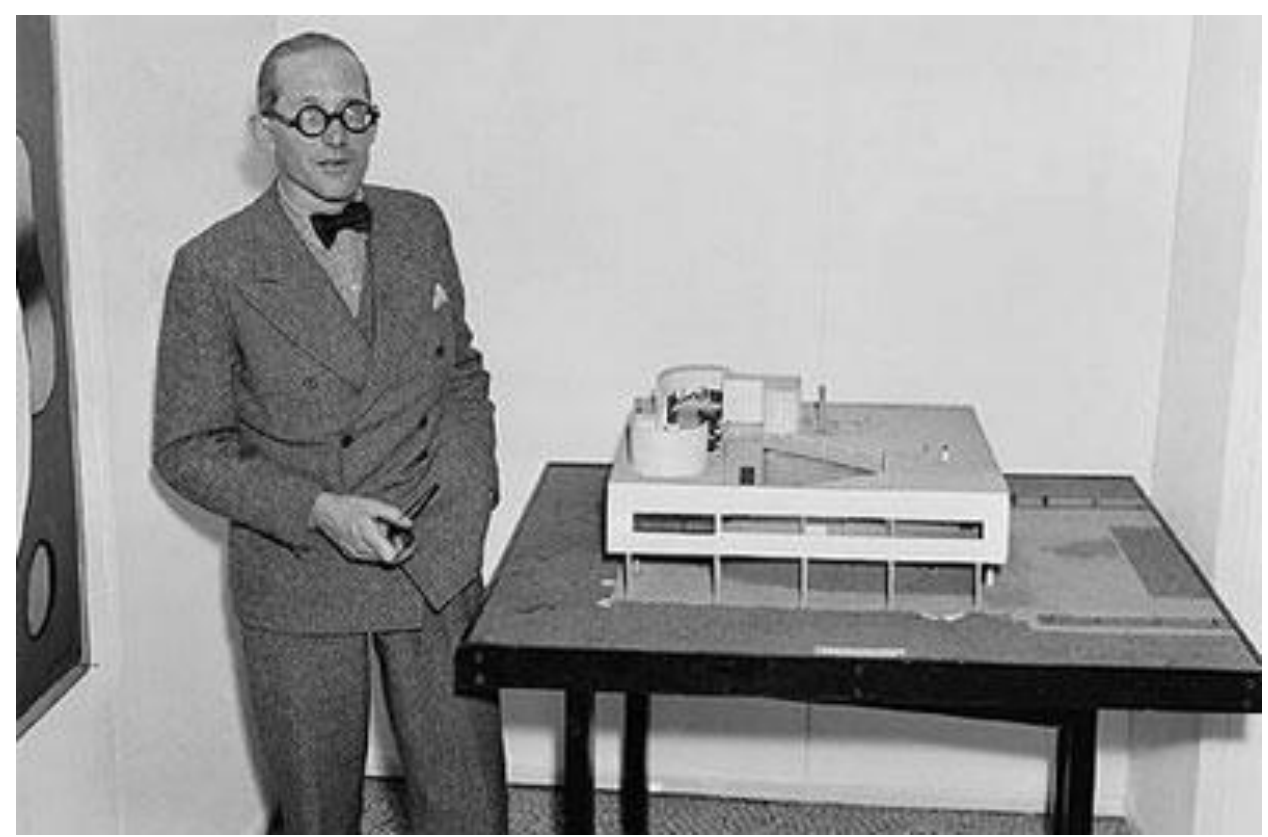

Figura 1. Le Corbusier junto a la maqueta de la Ville Savoy, construida en Poissy, París, en 1929. En 1932 fue expuesta en el MoMA de Nueva York. 
LAPEÑA GALLEGO, Gloria (2016): "El lenguaje fotográfico de maquetas arquitectónicas como forma de expresión creativa". Ángulo Recto. Revista de estudios sobre la ciudad como espacio plural, vol. 8, núm. 1-2, pp. 113-126. ISSN: 1989-4015.

http://dx.doi.org/10.5209/rev_ANRE.2016.v8.n1.53351

En la actualidad, algunas obras arquitectónicas se someten a discusión sobre su pertenencia al campo de las artes, hecho que va ligado a la tradicional asociación del arte a lo "bello" y la preocupación del arquitecto por no renunciar a unos preceptos estéticos en armonía con los gustos de la sociedad, respetando las características técnicas que deben reunir los edificios.

La conexión de la maqueta con el arte tiene que ver con su conexión con el dibujo, la comunicación y la expresión gráfica y, al igual que el arte contemporáneo, no solo es el producto final en tanto que objeto, sino también su proceso de elaboración, capaz de implicar al espectador en la reflexión. Y esta reflexión no se realiza delante de la propia maqueta, sino delante de la imagen fotográfica de la maqueta. El apoyo para cualquier artículo de investigación será una fotografía y, a la hora de mostrar un proyecto, los paneles explicativos no presentan la maqueta física, sino vistas desde distintos ángulos de la maqueta, a veces manipulados por técnicas de postimagen (Saga 2014).

\section{El arquitecto y el artista: puntos de encuentro}

La ejecución de una obra arquitectónica implica una serie de fases previas de elaboración del proyecto (potencia) antes de concluir en la obra de arquitectura o ingeniería (acto). El proyecto, además de las especificaciones y documentación técnica, consta de una serie de formas bidimensionales (dibujos y planos) y tridimensionales (maquetas) que actualmente se realizan con programas informáticos, ciñéndose a unos principios físicos, químicos y matemáticos, y a una legislación. La representación de ciudades enteras mediante maquetas urbanas para producciones cinematográficas y juegos es un terreno a caballo entre arquitectura y arte. La maqueta descontextualizada se configura como una fábula o imagen fantasiosa que evoca determinadas sensaciones en el receptor.

No es el objetivo de este trabajo valorar la inclusión o no de las maquetas como obras de arte, tema ampliamente discutido en el artículo de Ríos Ruiz (2011), que arranca del Convenio de Berna (art. 2.1), en el que se califica con el término de obras literarias y artísticas a "[...] las obras de dibujo, pintura, arquitectura, escultura, grabado y litografía; las obras fotográficas a las cuales se asimilan las expresadas por procedimiento análogo a la fotografía; las ilustraciones, mapas, planos, croquis y obras plásticas relativos a la geografía, a la topografía, a la arquitectura o a las ciencias". Este estudio concluye que no solo las obras de arquitectura, sino también sus respectivos proyectos arquitectónicos, planos y maquetas, están protegidos por las normas vigentes sobre derecho de autor, y como tales son obras de arte. 
LAPEÑA GALLEGO, Gloria (2016): "El lenguaje fotográfico de maquetas arquitectónicas como forma de expresión creativa". Ángulo Recto. Revista de estudios sobre la ciudad como espacio plural, vol. 8, núm. 1-2, pp. 113-126. ISSN: 1989-4015.

http://dx.doi.org/10.5209/rev_ANRE.2016.v8.n1.53351

Algunos artistas, especialmente fotógrafos, utilizan en sus obras maquetas similares a las arquitectónicas, elaboradas con fines muy diferentes a los de Le Corbusier. Beatriz Colomina (1992) explica gráficamente, casi con ironía, la diferencia entre el arquitecto, quien mira a través del objetivo y realiza muchas tomas desde distintos ángulos, y el fotógrafo artista, para quien la maqueta solo existe en la posición en la que esta es fotografiada.

\section{El artista como constructor de maquetas}

Con el propósito de analizar la labor de artistas que construyen maquetas sin una finalidad técnica, sino puramente artística, nos hemos centrado en los trabajos, recogidos en sendos catálogos o libros de artista, de James Casebere (2003), Thomas Demand (2008), Ignacio Llamas (2010 y 2013) y Gloria Lapeña (2014). En todos los casos podemos establecer similitudes con el arquitecto que diseña su obra en base a una estética pero, a diferencia de este, la acción del artista se amplía hacia la intencionalidad de crítica o reflexión frente una obra física para ser habitada.

\subsection{James Casebere}

Casebere (Lansing, Michigan, 1953) es pionero y uno de los máximos representantes de la fotografía arquitectónica. Su trabajo parte del cuestionamiento del género fotográfico como testimonio de la realidad, característica fundamental que lo ha distinguido tradicionalmente del resto de manifestaciones artísticas. Sus obras, en efecto, son fotografías de arquitecturas vacías y sumamente misteriosas, y sin embargo, nada de lo que vemos es real, sino una recreación. Para lograrlo, el artista lleva a cabo un proceso de creación que comienza con la construcción de las maquetas, de un tamaño no superior a una mesa, sin mucho detalle y a base de materiales neutros, como yeso, poliuretano, papel y cartón pluma. Son los dramáticos efectos de iluminación los que se convierten en la clave para transformar estas anodinas construcciones en espacios surrealistas.

Entre los meses de febrero y abril de 2003, se presenta en la Sala de Exposiciones del Joldo Mitxelena Kulturuneko Eurakustaretoa de San Sebastián la muestra Arquitecturas Excéntricas. En ella participan cinco artistas de reconocido prestigio internacional (James Casebere junto a Magdalena Jetelová, Tadashi Kawamata, Georges Rousse y Edwin Zwakman) bajo un tema común: arquitecturas que desarticulan su significado en el espacio cotidiano y que son presentadas como dobles, espectros y huellas. Casebere incluye en la muestra fotografías que recrean los grandes centros institucionales de confinamiento de Michel 
Foucault: fábricas, prisiones, cuarteles, hospitales psiquiátricos y otros interiores de aspecto mortecino que aíslan al ser humano de todo contacto con el mundo exterior.

Precisamente, gran parte del trabajo de este artista se centra en criticar de qué manera las estructuras mentales de poder, por medio de la arquitectura, son capaces de determinar el comportamiento del ser humano y definirlo como individuo. Two tunnels from right (1998) y Monticello (2001) se revelan al espectador con una belleza irracional (figura 2). La sensación de claustrofobia y aislamiento se consigue por medio de unos muros que crean opresión y la infiltración de agua que desgasta los cimientos.

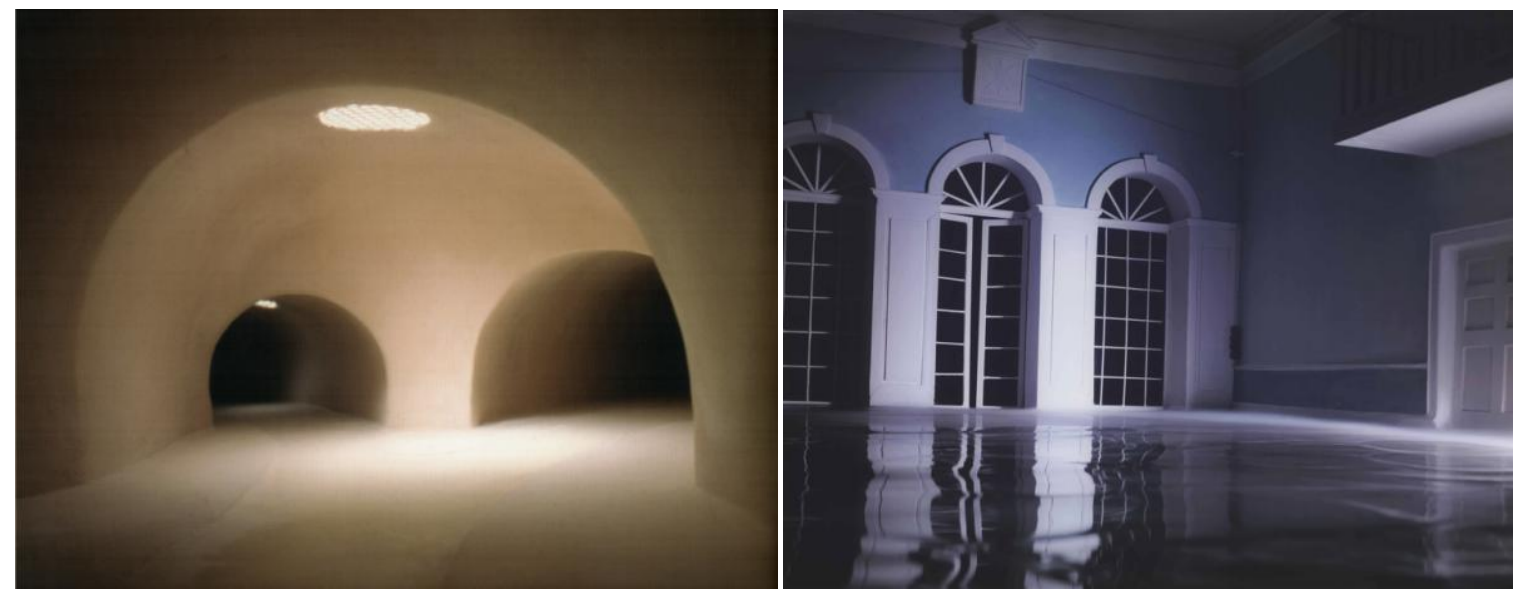

Figura 2. James Casebere, Two tunnels from right (1998) y Monticello \#3 (2001).

\subsection{Thomas Demand}

Para la construcción de sus maquetas, Thomas Demand (Munich, 1964) utiliza como referencia lugares controvertidos que han sido popularizados a través de los medios de comunicación de masas, que reconstruye a base de materiales humildes, como el papel y el cartón.

Demand participa en el XI Festival Internacional de Fotografía y Artes Visuales (Madrid, 2008) con su obra Cámara. Su serie fotográfica Klause (2006) está compuesta por cinco imágenes del interior y exterior de maquetas construidas a escala real que reproducen un negocio de restauración que en 2001 fue escenario del asesinato de un niño de cinco años por una banda de pederastas (figura 3). El proceso judicial, que duró tres años, se caracterizó por las continuas disputas y controversias, lo cual generó una campaña emocional sin precedentes por parte de los medios de comunicación. Mientras la prensa sensacionalista y la televisión mostraron imágenes y testimonios 
escabrosos sobre el suceso, la obra de Thomas Demand no se presta a una manipulación moral ni a la competición en la veracidad. A pesar de que las cinco fotografías han sido tomadas desde el mismo punto de vista que las que fueron publicadas por la prensa, no hay intención de engañar al espectador haciéndole pensar que se trata de los originales, sino todo lo contrario: la excesiva limpieza y la ausencia de imperfecciones en los espacios evidencian claramente el artificio de las imágenes. Con ello, Demand sugiere que si, a pesar de todo, el espectador pasa por alto estos detalles, la causa no será un exceso de realismo, sino la excesiva rapidez con la que nos hemos acostumbrado a mirar (consumir) las imágenes con las que nos bombardean a diario, y por ende, el mundo que nos rodea (Gómez Isla 2005).

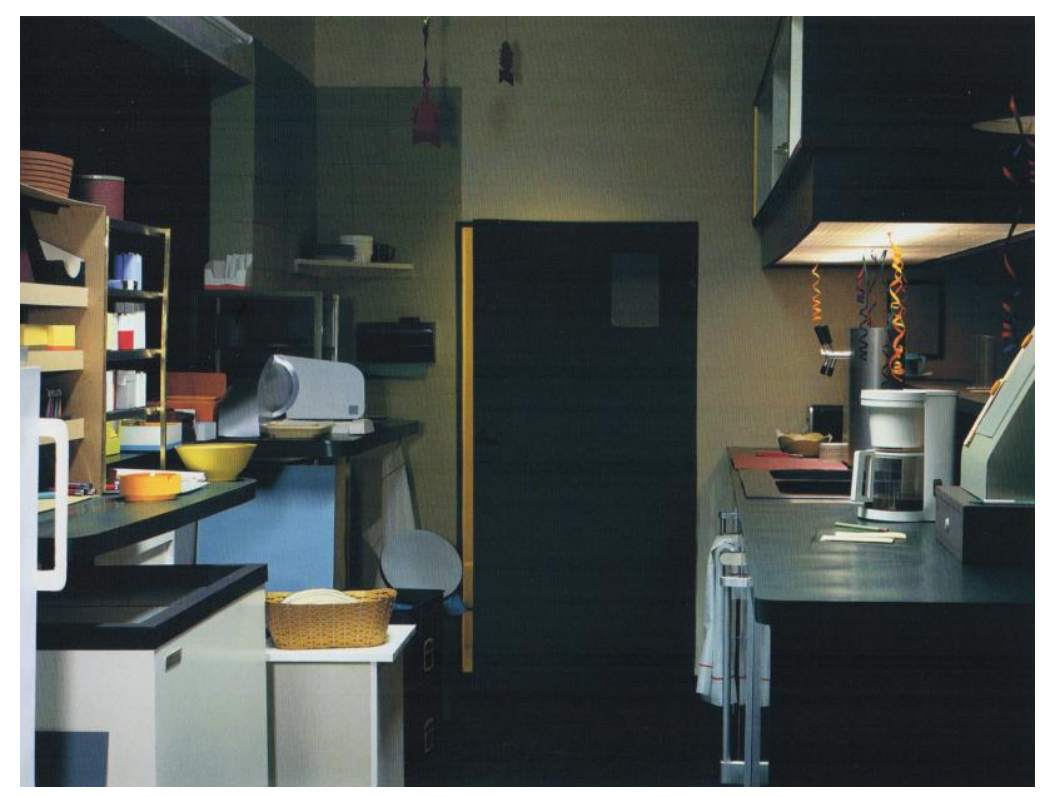

Figura 3. Thomas Demand, Klause III (2006).

\subsection{Ignacio Llamas}

Ignacio Llamas (Toledo, 1970) utiliza la arquitectura como metáfora del mundo interior del ser humano, a través de espacios aparentemente deshabitados, caracterizados por la sobriedad y la ausencia de color, pero inundados de una luz suave y difusa que es capaz de transformar y matizar esos lugares inquietantes y desoladores, convirtiéndolos en espacios de paz y sosiego.

En sus exposiciones Disipar el lamento (Toledo, 2010) y Fisuras (Valladolid, 2013), acompaña sus fotografías de los escenarios utilizados, realizados a pequeña escala y encerrados en cajas (en algunos casos sobresaliendo de la pared; en otros, sostenidas por sus 
propias patas), dejando tan solo unas pequeñas aberturas por las que deslizar la mirada hacia su interior (figura 4). La mirada se dirige, guiada por su instinto, hacia la luz, pero en su camino se encuentra con una serie de objetos que bloquean los límpidos espacios: maletas y sillas abandonadas, escaleras, esqueletos de árboles... Son pequeños accidentes que hacen evidente la existencia de ciertas heridas, determinados "desperfectos", pero que dejan de estorbar disueltos en esa atmósfera, que los transforma, haciéndolos esenciales para la obra. Se trata, en definitiva, de permitir al espectador asomarse a su propia alma, de reconocer la luz existente en ella y de asumir sus penumbras y oscuridades (Llamas 2012-2013).

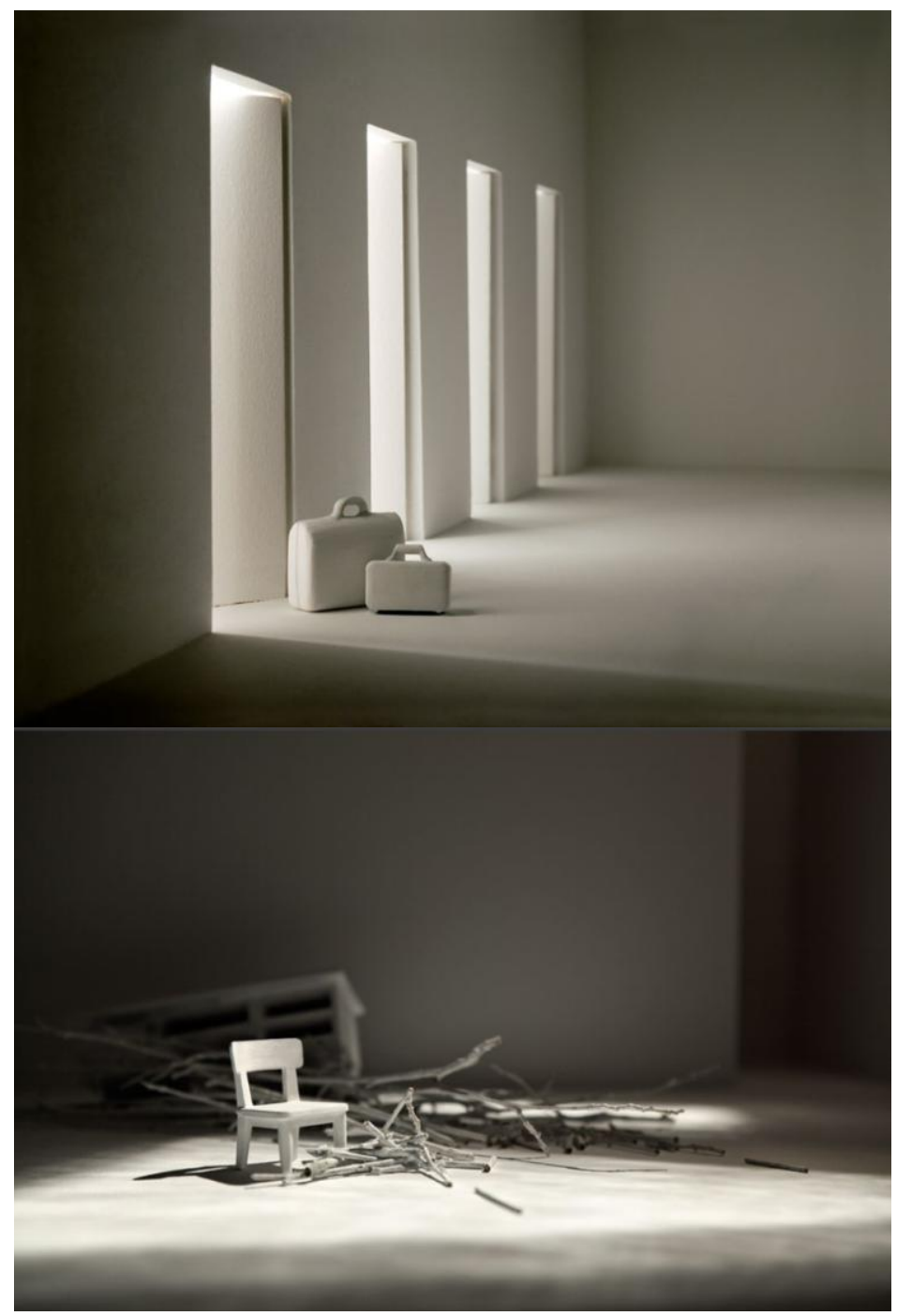

Figura 4. Ignacio Llamas, Obra de la serie Disipar el lamento (2010) (arriba) y Obra de la serie Fisuras (2013) (abajo). 


\subsection{Gloria Lapeña}

La figura humana ha sido la gran ausente en la fotografía de arquitecturas. A diferencia de los trabajos anteriores, la obra de Gloria Lapeña (Murcia, 1989) titulada El espacio que habit(ú)a introduce el cuerpo humano, concretamente el femenino, aunque sin mostrar en ningún momento su identidad, presentándolo como mero soporte sobre el que se asientan las arquitecturas.

El espacio doméstico ha constituido tradicionalmente el lugar natural de la mujer (el que habita) al mismo tiempo que ha condicionado su imagen, teniendo que adaptarse (habituarse) a los estándares familiares, diseñados por y para el hombre. El espacio que habit(ú)a es un proyecto seleccionado para participar en el Festival Miradas de Mujer 2014. Conjuga el cuerpo femenino y la maqueta arquitectónica para reflexionar sobre el sometimiento de la mujer en el ámbito privado, un lugar que nunca le ha pertenecido realmente, y donde su función se ha visto restringida a servir de sustento o pilar, elemento necesario, pero no valorado e invisibilizado. El título resume la doble función de la casa como piel protectora y como elemento que encasilla y subvierte.

La muestra se compone de una serie de cuatro fotografías que presentan un modelo de vivienda minimalista que se caracteriza por la volumetría cúbica. La rigidez de las casas obliga al cuerpo a adoptar posturas forzadas, creando un diálogo de sumisión y adaptación. Los planos para su construcción se presentan como los patrones de costura para la confección de una prenda de ropa femenina. En cada uno de los cuatro patrones se indican las funciones específicas de cada prenda, haciendo alusión a los accesorios fetiche. La finalidad es adoptar posturas físicas que resulten atractivas desde el punto de vista sexual: "Para elevar el pie, estilizar la pierna y conseguir unos andares sensuales" (Confección n. ${ }^{\circ}$ 1) (figura 5); "Para alargar el cuello, levantar la barbilla y conseguir un porte elegante" (Confección n.o 2); "Para elevar los glúteos y pronunciarlos" (Confección n.o 3); "Para elevar los senos" (Confección n. 0 4). 
LAPEÑA GALLEGO, Gloria (2016): "El lenguaje fotográfico de maquetas arquitectónicas como forma de expresión creativa". Ángulo Recto. Revista de estudios sobre la ciudad como espacio plural, vol. 8, núm. 1-2, pp. 113-126. ISSN: 1989-4015.

http://dx.doi.org/10.5209/rev_ANRE.2016.v8.n1.53351

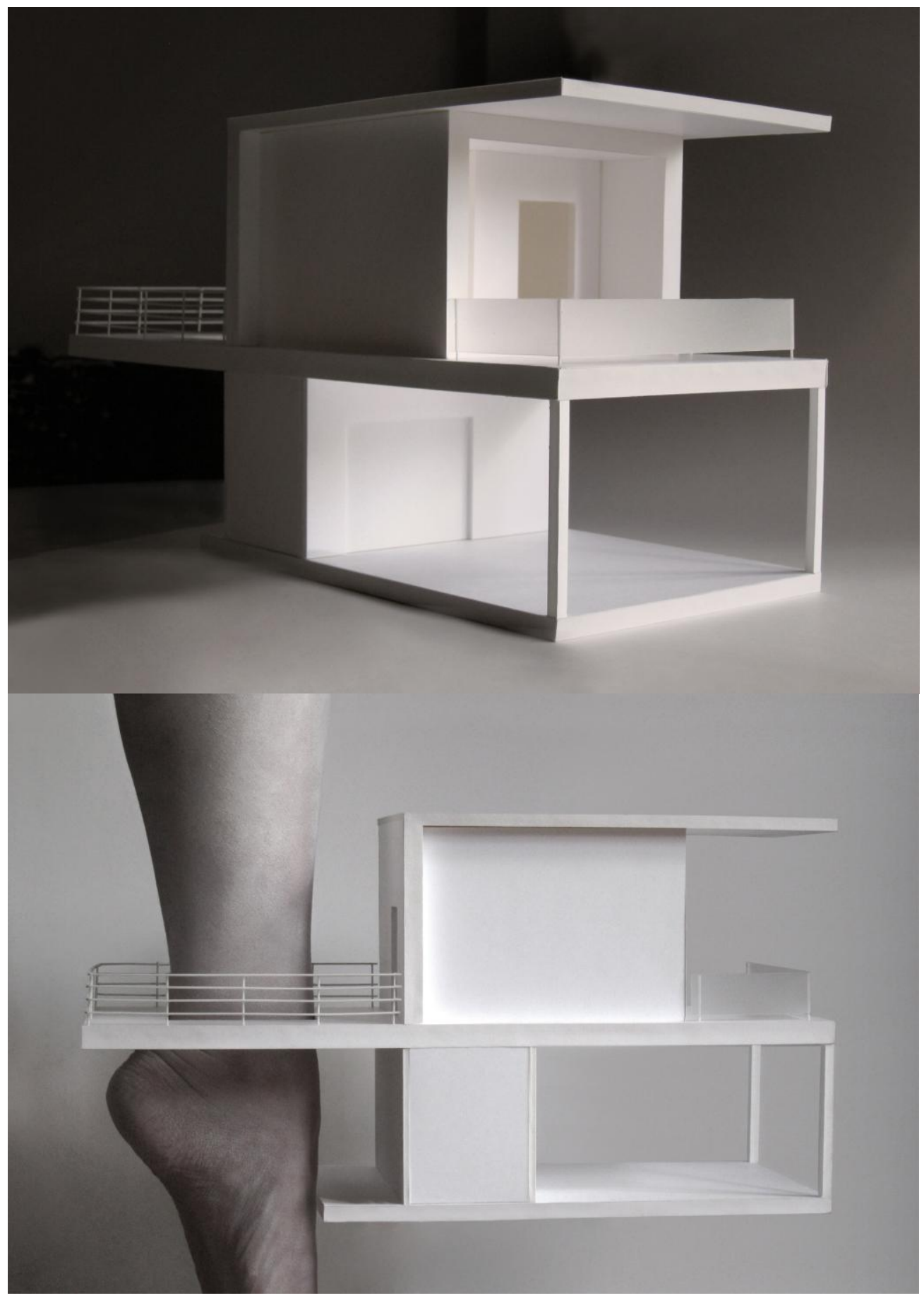

Figura 5. Gloria Lapeña, Confección n.o 1 maqueta (2014) (arriba) y fotografía (2014) (abajo).

\section{Conclusiones}

La construcción de maquetas a partir de planos o bocetos es uno de los pasos previos del arquitecto para la construcción de un edificio, pero 
LAPEÑA GALLEGO, Gloria (2016): "El lenguaje fotográfico de maquetas arquitectónicas como forma de expresión creativa". Ángulo Recto. Revista de estudios sobre la ciudad como espacio plural, vol. 8, núm. 1-2, pp. 113-126. ISSN: 1989-4015.

http://dx.doi.org/10.5209/rev_ANRE.2016.v8.n1.53351

también es una herramienta utilizada por algunos artistas para fijar la atención sobre determinados planos de casas imaginarias, a veces imposibles de habitar, y que captan con el objetivo de la cámara. En ambos casos, la obra final es un producto pensado para la sociedad, pero mientras que en el primero la funcionalidad debe ser la principal finalidad, el fotógrafo artista centra su atención en despertar en el espectador la reflexión hacia temas familiares y cotidianos generados por la tensión estructural que ocasionan la relocalización y resignificación arquitectónica.

Las cuatro exposiciones que hemos recorrido construyen y fotografían maquetas arquitectónicas, un proceso similar al de la fase de proyección de un edificio para ser habitado, pero sin rastro de habitantes. Los textos publicados en los catálogos de las exposiciones fotográficas consultadas hablan de soledad, de luz, de diálogo íntimo y de discriminación de la mujer, sin incluir imágenes explícitas sobre cada uno de los temas abordados por los cuatro artistas.

\section{Bibliografía}

CASEBERE, JAMES (2013): Arquitecturas Excéntricas. San Sebastián: Sala de Exposiciones del Joldo Mitxelena Kulturuneko Eurakustaretoa.

COLOMINA, Beatriz (1992): Sexuality and Space. Nueva York: Princeton Architectural Press.

DEMAND, Thomas (2008): Cámara. Madrid: Patronato de la Fundación Telefónica.

DONDIS, Donis A. (1980): La sintaxis de la imagen: Introducción al alfabeto visual. Barcelona: Gustavo Gili.

FALCÓN MERAZ, José Manuel (2008): La expresión de una línea museística singular. Tesis Doctoral. Barcelona: Universidad Politécnica de Cataluña.

GÓMEZ ISLA, José (2005): Arte hoy: Fotografía de creación. San Sebastián: Editorial Nerea.

HERGUETA PIORNO, Isabel (2012): "Loos en su época. Convergencia estética con la filosofía de Wittgenstein". Ab Initio, vol. 6, pp. 2946.

LAPEÑA, Gloria (2014): El espacio que habit[ú]a. Mula: Fundación Casa Pintada / Museo Cristóbal Gabarrón.

LE CORBUSIER (Charles-Édouard Jeanneret) (1978): Hacia una arquitectura. Barcelona: Apóstrofe.

LE CORBUSIER (Charles-Édouard Jeanneret) (2008): Le Corbusier: Vers une architecture. París: Flammarion.

LLAMAS, Ignacio (2010): Disipar el lamento. Toledo: Galería Tolmo. 
LAPEÑA GALLEGO, Gloria (2016): "El lenguaje fotográfico de maquetas arquitectónicas como forma de expresión creativa". Ángulo Recto. Revista de estudios sobre la ciudad como espacio plural, vol. 8, núm. 1-2, pp. 113-126. ISSN: 1989-4015.

http://dx.doi.org/10.5209/rev_ANRE.2016.v8.n1.53351

LLAMAS, Ignacio (2012-2013): Fisuras. Valladolid: Museo de Arte Contemporáneo del Patio Herreriano.

LOOS, Adolf (1993): Escritos II 1910-1933. Madrid: El Croquis.

PLÁ, Maurici; GARNICA, Julio; y ESPARZA, Verónica (2006): "Escala urbana y escala arquitectónica: maquetas". DC. Revista de crítica arquitectónica, núm. 15-16, pp. 73-79.

RÍOS RUIZ, Wilson Rafael (2011): "La obra de arquitectura y los proyectos arquitectónicos y su proyección en la legislación sobre el derecho de autor". Revista de la Propiedad Inmaterial, núm. 15, pp. 143-168.

SAGA, Manuel (2014): "Maquetas urbanas: Fábulas a escala" [en línea]. BlogURBS. Estudios urbanos y ciencias sociales, 21 de enero de 2014. En: http://www2.ual.es/RedURBS/BlogURBS/maquetasurbanas-fabulas-a-escala/ [Consulta: 16/07/2017].

ÚBEDA BLANCO, Marta (2002): La maqueta como experiencia del espacio arquitectónico. Valladolid: Universidad de Valladolid.

ZUGMANN, Gerald (2002): Blue Universe: Modelle zu Bildern machen = Blue Universe: Transforming Models into Pictures. Architectural Projects by CoopHimmelb(L)au. Otsfildern-Ruit: Hatje Cantz. 